Shella May A. Promentilla, MD

Rubiliza DC. Onofre, MD,

Benjamin SA. Campomanes, Jr., MD

Department of Otorhinolaryngology

Head and Neck Surgery

East Avenue Medical Center
Correspondence: Dr. Shella May A. Promentilla

Department of Otorhinolaryngology - Head and Neck Surgery 6th floor East Avenue Medical Center

East Avenue, Quezon City 1100

Philippines

Phone: (632) 9280611 local 324

Email:eamc_enthns@yahoo.com

The authors declared that this represents original material that is not being considered for publication or has not been published or accepted for publication elsewhere in full or in part, in print or electronic media; that the manuscript has been read and approved by all the authors, that the requirements for authorship have been met by each author, and that each author believes that the manuscript represents honest work.

Disclosure: The nasal packs were provided by Nasopore Forte ${ }^{\oplus}$ (EASMED SDN BHD 13th Floor Suite 13.05 \& 13.06 Menara Summit Persiaran Kewajipan, USJ 147600 UEP Subang Jaya Selangor Darul Ehsan, Malaysia) for the course of this study. However, the company did not influence the conduct and results of this study since the primary objective was to determine the effects of Dexamethasone as a topical corticosteroid in the management of post-ESS nasal cavity, and not examine the characteristic of the pack as vehicle for the drug.

Presented at the Philippine Society of Otolaryngology Head and Neck Surgery Analytical Research Contest (2nd Place), Plaza Ibarra,Quezon Avenue, Quezon City, November 10, 2015.

\section{Effects of Dexamethasone versus Saline-Impregnated Nasal Packing on the Postoperative Outcome of Patients with Chronic Rhinosinusitis and Nasal Polyps after Endoscopic Sinus Surgery: A Randomized Controlled Trial}

\begin{abstract}
Objectives: To evaluate the effects of Dexamethasone-impregnated absorbable nasal pack versus saline-impregnated nasal packing on postoperative outcome of nasal cavities after endoscopic sinus surgery using the Perioperative Sinus Evaluation Scoring System (POSE) and Lund and Kennedy Endoscopic Scoring System.
\end{abstract}

\section{Methods:}

Design: Prospective, randomized, double blinded, placebo-controlled trial Setting: $\quad$ Single Center Tertiary Government Hospital

Participants: Nineteen (19) patients aged 15 years old and above, diagnosed with chronic rhinosinusitis, with nasal polyposis grade 3 , who underwent endoscopic sinus surgery from January 2015 to August 2015

Results: Nasal cavities that received postoperative dexamethasone-impregnated nasal packs showed significantly lower POSE scores than placebo on post-op Days 14 (p value 0.0022; 95\% $\mathrm{Cl}$ - -2.113 to -0.5116 ) as well as lower Lund-Kennedy Scores on post-op day 14 ( $\mathrm{p}$ value of 0.0180 ; $95 \% \mathrm{Cl}:-2.493$ to -0.2571 ) and day 28 ( $\mathrm{p}$ value of $0.007 ; 95 \% \mathrm{Cl}:-1.56275$ to -0.2832 ).

Conclusion: Dexamethasone-impregnated absorbable nasal packing affords better postoperative outcomes: less edema, crusting, secretions, and synechiae, than saline-impregnated absorbable packing in later postoperative days.

Keywords: Dexamethasone, endoscopy, nasal polyp, nasal cavity, intranasal absorption

Functional endoscopic sinus surgery (ESS) has become the standard treatment for medically refractory chronic rhinosinusitis and nasal polyps. ${ }^{1}$ Advancements in post-ESS care include the use of nasal packing and steroids. New absorbable nasal packs provide less pain, bleeding, nasal blockage, and facial edema. ${ }^{2}$ Intranasal steroids also decrease mucosal inflammation and minimize nasal secretory response, and Triamcinolone Acetonide and Mometasone-impregnated absorbable nasal packing post-ESS have shown promising postoperative results. ${ }^{3.4}$ However, further studies are needed, and we wanted to find out whether impregnating absorbable nasal 
packs with Dexamethasone, a more widely available, long acting steroid, ${ }^{5}$ can similarly demonstrate better postoperative outcomes.

This study aimed to objectively measure the effects of Dexamethasone-impregnated packing versus saline-impregnated packing on post-ESS nasal cavities.

\section{METHODS}

\section{Study design and Setting}

This prospective, randomized, double blinded, placebo-controlled trial was conducted in a tertiary government hospital from January 1 , 2015 to August 31, 2015.

\section{Population and Sample Size}

The study was conducted among patients 15 years old and above, diagnosed with chronic rhinosinusitis with nasal polyposis grade 3 , bilateral. Patients with recurrent nasal polyposis; previous history of ESS and medical co-morbidities were excluded from the study. Informed consent and assent were obtained.

The target population was computed based on proportion estimate outcomes. P1 .800 ( $8 \%$ chance of morbidity) and p2 .300 (3\% chance of morbidity) with a margin of error of $5 \%$ and power of $90 \%$. A minimum total of 32 nasal cavities, 16 in each treatment group, was needed to be $90 \%$ sure of being able to detect a $5 \%$ reduction in postoperative morbidity, which was felt to be clinically relevant.

\section{Sample Size Computation}

$m($ Size per group $)=c \times \frac{p 1(1-p 1)+p 2(1-p 2)}{(p 1-p 2)^{2}}$

$$
\begin{array}{cc}
\begin{array}{l}
\mathrm{p} 1=.800 \\
\mathrm{p} 2=.300
\end{array} & \begin{array}{c}
\text { margin of error } 5 \% \\
\text { power } 90 \%
\end{array} \\
\mathrm{~m} & =\frac{10.5 \times .800(1-.800)+.300(1-.300)}{(.800-.300)^{2}} \\
\mathrm{~m} & =\frac{10.5 \times .800(0.2)+.300(0.7)}{0.25} \\
\mathrm{~m} & =\frac{10.5 \times 0.16+0.21}{0.25} \\
\mathrm{~m} & =\frac{10.5 \times .37}{0.25} \\
\mathrm{~m} & =3.885 / 0.25 \\
\mathrm{~m} & =15.54 \sim 16 \\
\text { sample size }=16 \times 2=32 \text { nasal cavities }
\end{array}
$$

A table of random numbers was used in labeling patients. All odd numbered patients were given Dexamethasone packing on their left nasal cavity, placebo saline packing on their right, and vice versa. The allocation of impregnated packs was not known to the participants, surgeons and postoperative evaluators.

\section{Clinical Trial}

Nasal packs were composed of two equal dimensions of $8 \mathrm{~cm} \times 2 \mathrm{~cm}$ x $1 \mathrm{~cm}$ biodegradable synthetic polyurethane foam (Nasopore Forte ${ }^{\oplus}$, EASMED SDN BHD Subang Jaya Selangor Darul Ehsan, Malaysia), one soaked with $2 \mathrm{ml}$ of $4 \mathrm{mg} / \mathrm{ml}$ Dexamethasone and the other with $2 \mathrm{ml}$ saline solution.

After endoscopic sinus surgery, the surgeon placed the nasal packs in the assigned nasal cavity as dictated by the investigator. All patients were given Co-Amoxiclav 625mg/capsule, 1 capsule every 8 hours for 7 days as postoperative prophylaxis. Saline nasal douching was commenced on the $4^{\text {th }}$ postoperative day.

Nasal endoscopy was performed on postoperative days $3,7,14$, and 28 before and after nasal saline irrigation and removal of blood clots.

\section{Data Collection}

A blinded otorhinolaryngology consultant who was not a coinvestigator assessed all nasal endoscopy videos in one sitting using the Perioperative Sinus Endoscopic (POSE) ${ }^{6}$ and Lund-Kennedy Sinus Endoscopy ${ }^{2}$ score sheets. These are objective endoscopic scoring tools used for assessing sinonasal cavities. ${ }^{2,6}$ Crusting, mucosal edema, polyposis, secretions and scarring criteria for assessment are found in both tools. In addition, the POSE system has middle turbinate, middle meatal antrostomy and secondary sinuses as additional assessments. ${ }^{6}$ Fully accomplished scoring sheets were collated and tallied for analysis.

\section{Statistical Analysis}

Descriptive statistics were described using mean, standard deviation, frequency and median. The difference between Dexamethasone and placebo group scores on each evaluation day was determined using student paired t-test. Repeated Measurement Analysis of Variance, RMANOVA at $<0.05 p$-value was utilized for multivariate analysis between each evaluation day. STATA 12.0 (StataCorp LP., Texas USA) was used for data encoding and analyses.

\section{Ethical Considerations}

The department research ethical board alone evaluated the study, since a hospital IRB was not yet established at that time. The study 


\section{ORIGINAL ARTICLES}

adhered with the ethical principles set out in relevant guidelines (Declaration of Helsinki 2008, WHO Operational Guidelines, ICH-GCP and National Ethics Guidelines for Health Research). Written and informed consent were obtained from all participants upon recruitment. Patients aged 15 to 18 years old were asked for an assent form prior to their inclusion to the study. All identifiable information was deleted from the data obtained with each participant assigned with unique al phanumeric codes. All data were kept in an external hard drive accessible only to the investigators, and will be kept for five years.

\section{RESULTS}

This study comprised 19 patients, 9 females and 10 males, with a range of 15 to 33 years old (median age, 31 years).

All underwent ESS, however one of the participants was withdrawn from the study because of severe postoperative bleeding and revision of nasal packing, thus, only 18 patients or 36 nasal cavities, were considered for final evaluation. There were also follow-up irregularities accounting for the differences in population for each evaluation made.

Mean POSE scores (Table 1) of the saline group on days 3 and 7 were higher than the Dexamethasone group. The scores of both groups improved on Day 7 of evaluation, but the differences between the two groups were not statistically significant.

The POSE scores on day 14 generally improved for both groups. The Dexamethasone nasal cavities had a 2-point lower score than the saline group with a $p$-value of 0.0022 , which was statistically significant (confidence interval of -2.113 to -0.5116 ).

Table 1. Perioperative Sinus Evaluation (POSE) Scores from Day 3 to Day 28 of post-ESS patients ( $\mathrm{n}=36$ nasal cavities)

\begin{tabular}{|c|c|c|c|c|c|}
\hline \multirow[t]{3}{*}{ Population } & Day3 & Day 7 & Day 14 & Day 28 & \multirow[t]{2}{*}{ P-value ${ }^{+}$} \\
\hline & $n=34$ & $n=34$ & $n=32$ & $n=26$ & \\
\hline & Mean (SD) & & & & \\
\hline $\begin{array}{l}\text { Dexamethasone } \\
\text { group }\end{array}$ & $\begin{array}{l}4.1765 \\
( \pm 1.382)\end{array}$ & $\begin{array}{l}3.0588 \\
( \pm 1.2112)\end{array}$ & $\begin{array}{l}1.875 \\
( \pm 1.0879)\end{array}$ & $\begin{array}{l}1.3077 \\
( \pm 1.2016)\end{array}$ & $<0.0001^{\# a}$ \\
\hline Placebo group & $\begin{array}{l}4.6471 \\
( \pm 1.6066)\end{array}$ & $\begin{array}{l}3.7059 \\
( \pm 0.8921)\end{array}$ & $\begin{array}{l}3.1875 \\
( \pm 1.1302)\end{array}$ & $\begin{array}{l}1.7692 \\
( \pm 1.4226)\end{array}$ & $0.000116^{\# a}$ \\
\hline P-value* & $\begin{array}{l}-0.9158 \\
(-1.5186 \text { to } \\
0.5775)\end{array}$ & $\begin{array}{l}-1.77391 \\
(-1.3932 \text { to } \\
0.09897)\end{array}$ & $\begin{array}{l}0.0022^{\#} \\
(-2.113 \text { to } \\
-0.5116)\end{array}$ & $\begin{array}{l}-0.893566 \\
(-1.5299 \text { to } \\
0.6069)\end{array}$ & \\
\hline
\end{tabular}

\# Significance of P-value based on corresponding Confidence Intervals a significant also at $P$-value $<0.05$

* Student T-test used in determining difference between two groups

+ RM-ANOVA used in determining differences between each evaluation days
Table 2. Lund-Kennedy Sinus Endoscopy scores from postoperative Day 3 to Day 28 of post-ESS patients ( $\mathrm{n}=36$ nasal cavities)

\begin{tabular}{|l|l|l|l|l|l|}
\hline \multirow{3}{*}{ Population } & Day3 & Day 7 & Day 14 & Day 28 & \multirow{2}{*}{-value $^{+}$} \\
\cline { 2 - 5 } & $\mathrm{n}=34$ & $\mathrm{n}=34$ & $\mathrm{n}=32$ & $\mathrm{n}=26$ & \\
\cline { 2 - 5 } & Mean (SD) & & Mean $(\mathrm{SD})$ & Mean $(\mathrm{SD})$ & \\
\hline Dexamethasone & 4.765 & 3.588 & 2.250 & 0.462 & $<0.0001^{\text {\#a }}$ \\
group & $( \pm 1.262)$ & $( \pm 1.325)$ & $( \pm 1.854)$ & $( \pm 0.929)$ & \\
\hline Placebo group & 4.647 & 3.412 & 3.625 & 1.385 & $<0.0001^{\text {\#a }}$ \\
& $( \pm 1.326)$ & $( \pm 0.771)$ & $( \pm 1.130)$ & $( \pm 0.606)$ & \\
\hline P-value* $^{*}$ & 0.7921 & 0.6399 & $0.0180 \#$ & $0.007 \#$ & \\
& $(-0.7863$ to & $(-0.5882$ to & $\begin{array}{l}(-2.493 \text { to } \\
-0.2571)\end{array}$ & $\begin{array}{l}(-1.56275 \text { to } \\
-0.2832)\end{array}$ & \\
\hline & $1.02235)$ & $0.9403)$ & $-0.253)$ & \\
\hline
\end{tabular}

\# Significance of P-value based on corresponding Confidence Intervals a Significant also at $P$-value $<0.05$

* Student T-test used in determining difference between two groups

${ }^{+}$RM-ANOVA used in determining differences between each evaluation days

The POSE scores on day 28 showed greater general improvement with the Dexamethasone group registering a mean score of 1.3077 against 1.7692 of the placebo group. However, the difference between the groups was not statistically significant ( $p$-value of -0.8936 , based on confidence interval of -1.5299 to 0.6069 ).

A similar trend was seen using the Lund-Kennedy scoring system. (Table 2) On postoperative days 3 and 7, the differences were not statistically significant. Post-op days 14 and 28 , however showed that the Dexamethasone group scored 1 point lower than the placebo group, which was statistically significant with a p-value of 0.0180 based on confidence interval of -2.493 to -0.2571 (Day 14) and a $p$-value of 0.007 based on the confidence interval of -1.563 to -0.2832 (Day 28).

The RM- ANOVA was performed separately on the scores of both groups obtained from the 4 evaluation days. The decreasing scores between each examination day obtained for both POSE and LundKennedy scoring systems (Figure 1 and 2 ) were all statistically significant with $p$-values of $<0.05$ (Tables 1 and 2).

\section{DISCUSSION}

The effectiveness of performing ESS in patients with chronic rhinosinusitis with nasal polyps is dependent on the reduction of postoperative complications: scarring, edema and crusting which hinders natural ciliary function and sinus drainage. ${ }^{3}$ Several postoperative adjuncts developed include saline irrigation, meticulous nasal cavity cleaning as well as the use of topical steroid sprays. These practices have decreased the incidence of complications. ${ }^{1,7}$ To measure the postoperative improvements, this study utilized the 
POSE and Lund-Kennedy sinus endoscopic surgery scoring system, which incorporates crusting, mucosal edema, polyposis, secretions and scarring in their criteria. ${ }^{2,6}$ The benefit of postoperative packing was exemplified by the statistically significant progressive decrease in scores throughout the 28-day postoperative period. (Figure 1)

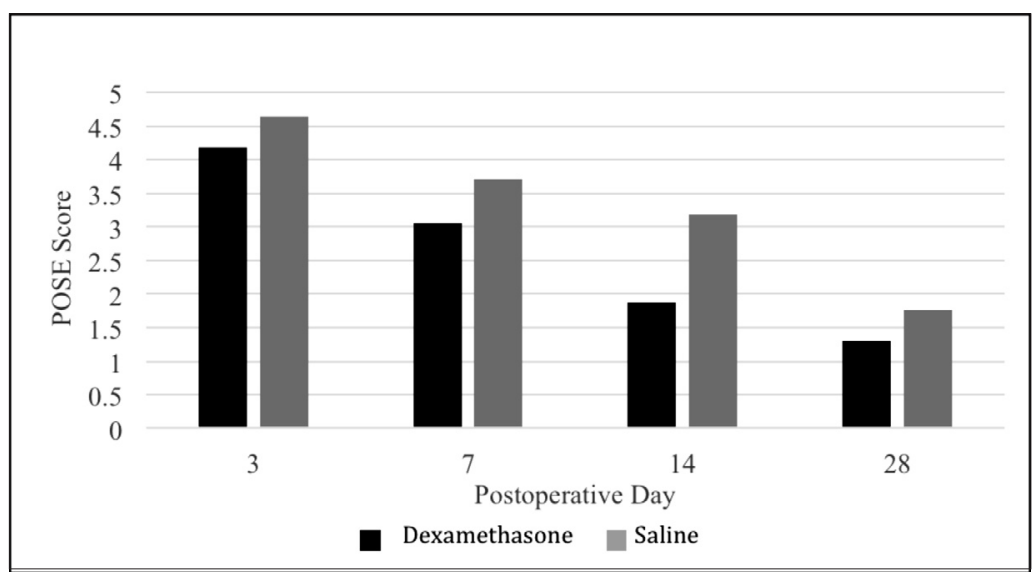

Figure 1. Comparison of post ESS nasal cavities dexamethasone impregnated nasal pack versus saline impregnated nasal pack based on mean Perioperative Sinus Evaluation scores

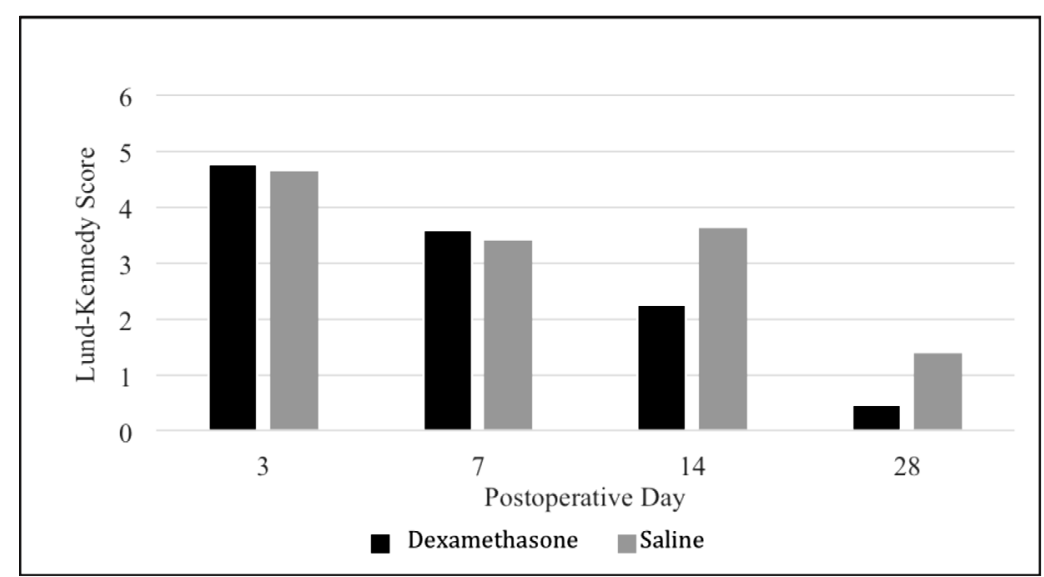

Figure 2. Comparison of post ESS nasal cavities dexamethasone impregnated nasal pack versus saline impregnated nasal pack based on mean Lund-Kennedy Sinus Endoscopy scores

In the management of post-ESS nasal cavities, steroids, both administered systemically or topically, had the widest range of studies regarding improved postoperative outcome. ${ }^{4,6,8}$ Administration of systemic steroids is known to improve short-term post-ESS outcomes. ${ }^{6}$ However, the risk of systemic side effects has led to the development of safer topical steroid sprays and steroidimpregnated nasal packs.

Two previous studies have shown that the delivery of Triamcinolone through nasal packs showed statistically significant improvements in POSE and LundKennedy scores from day 7 to day 28 postoperatively, with similar outcomes compared to the oral steroids while limiting the systemic harmful effects. ${ }^{3,8}$ We selected Dexamethasone for this study not only because it is widely available in our setting and inexpensive, but also because it has the longest half-life and highest anti-inflammatory effect among steroids. ${ }^{5}$ Its use in this study revealed improved scores on postoperative days 14 to 28 , suggesting a probable equivalence to Triamcinolone in terms of effectiveness, but at a fraction of the cost.

As for the drug safety, although steroid-impregnated absorbable nasal dressing may have transient systemic effects -- serum cortisol and osteocalcin suppression ${ }^{6,7}$-- possible systemic side effects were not evaluated in this study.

There is still a lack of consensus regarding optimal perioperative nasal dressing and steroid regimens, and this study may forge new ground in the search for an ideal postoperative standard of care based on effectiveness, economy and availability.

The investigators recommend the use of Dexamethasoneimpregnated absorbable nasal packing in the management of post-ESS patients.

A future non-inferiority study between Dexamethasoneimpregnated nasal dressing and Triamcinolone-impregnated dressing utilizing a bigger sample size, and safety studies covering local and systemic adverse effects and complications are also recommended.

\section{ACKNOWLEDGEMENTS}

The primary investigators would like to acknowledge the fourth year and first year resident physicians of the Department of ORL-HNS East Avenue Medical Center for helping them in the recruitment, screening, surgery and data gathering for this research paper. Likewise, we also thank Dr. Dwight Alejo for the review and interpretation of the nasal endoscopy videos of the participants.

\section{REFERENCES}

1. Wang YP, Wang MC, Chen YC, Leu YS, Lin HC, Lee KS. The effects of Vaseline gauze strip, Merocel, and Nasopore on the formation of synechiae and granulation tissue in the middle meatus and the incidence of major postoperative bleeding after endoscopic sinus surgery. J Chin Med Assoc. 2011 Jan; 74(1):16-21.

2. Vermin A, Seneldir L, Naiboglu B, Karace CT, Kulekci S, Toros SZ, Oysu C. Role of nasal packing in surgical outcome for chronic rhinosinusitis with polyposis. Laryngoscope. 2014 Jul; 124(7):1529-35.

3. Cote DWJ, Wright ED. Triamcinolone-impregnated nasal dressing following endoscopic sinus surgery: a randomized, double blind, placebo-controlled study. Laryngoscope. 2010 Jun; 120(6):1269-1273.

4. Marple BF. Smith TL. Han JK. Gould AR. Jampel HD. Stambaugh JW. Mugglin AS Advance II: a prospective, randomized study assessing safety and efficacy of bioabsorbable steroid releasing sinus implants. Journ Oto Rhino Laryngol Head Neck Surg. 2011; 146(6):1004-1011.

5. Adrenal Cortico Steroids. In: Drugs and Facts Companions. $5^{\text {th }}$ edition. Facts and companions Inc.: St Louis; 1997:122-128.

6. Wright ED, Agrawal S. Impact of perioperative systemic steroids on surgical outcomes in patients with chronic rhinosinusitis with polyposis. Evaluation with novel Perioperative Sinus Endoscopy (POSE) scoring system. Laryngoscope. 2007 Nov; 117 (suppl. 115):1-28.

7. Hong SD, Kin JH, Dhing HJ, Kim HY, Chung SK, Chang YS. et al. Systemic effects and safety of Triamcinolone-impregnated nasal packing after endoscopic sinus surgery: A randomized, double-blinded, placebo-controlled study. Am Journ Rhinol Allergy. September-October 2013; 27(5):407-410.

8. More Y, Willen S, Catalano P. Management of early nasal polyposis using steroidimpregnated nasal dressing. Int Forum Allergy Rhinol. 2011 Sep-Oct; 1(5):401404 